\title{
Organizational Culture and Innovation: A Study of Banking Sector in Pakistan
}

\author{
LAL MUHAMMAD \\ PhD Scholar, Sarhad University of Science \& IT, Peshawar. \\ Email: 1almuhammad261@gmail.com \\ Tel: +923152011011 \\ Dr. SYED GOHAR ABBAS \\ Associate Professor, Sarhad University of Science \& IT, Peshawar. \\ MIAN MUHAMMAD WASEEM IQBAL \\ Lecturer, Sarhad University of Science \& IT, Peshawar.
}

\begin{abstract}
The basic purpose of the study is to find out the impact of organizational culture on innovation in the banking sector of Pakistan. For this study, the data was collected manually and online from 309 branch managers, operations managers, and unit heads from 25 scheduled banks through adapted questionnaires with 60 items of organizational culture and 28 items of innovation. The results revealed a positive correlation between organizational culture types (involvement, adaptability and mission) and innovation in banks whereas consistency has negative correlation with innovation in banks. Individual analysis in not taken in the study and no comparisons made between the organizational cultures of different banks.
\end{abstract}

Keywords: Organizational Culture, Innovation, Involvement, Consistency, Adaptability, Mission.

\section{Introduction}

Human resource along with other factors is one of the most important factors of production in any organization. Every organization tries to manage its human resources effectively for getting a competitive advantage in this era of innovation and cutthroat competition and organizational culture play a pivotal role in this regard. Organizational culture being an important ingredient of any organization may foster or hinder the behaviors of the employees individually and collectively. Organizational and individual performances are highly influenced by organizational culture. To study the organization's philosophy, it is essential to know the theoretical aspects of the organizational culture. There is a lot of work done on organizational culture in different eras as it is an important as well as alarming factor which needs to be taken seriously by the organizations. Organizational culture varies from organization to organization and is resistant to change. Different researchers defined it differently and there is still a debate on what else to be included in its domain e.g.

"Organizational culture as a particularistic system of symbols shaped by ambient society and organization's history, leadership and contingencies, differentially shared, used and modified by actors in the course of acting and making sense out of organizational events" (Allaire \& Firsirotu, 1984).

According to Schein (1990) organizational culture is the interdependence of shared beliefs, behaviors and assumptions which are developed for problem solving and it must help the new employees to understand 
the core values, perceive reality and think positively about the organizational performance; Organizational culture is the invisible force within organizational structures which maintains overall organizational operations (Rahman, 2014). Innovations come from different factors which may be internal or external factors. Organizational culture is a primary element of the internal environment; which promotes innovative capabilities in the organization. Zheng (2009) pointed out that the innovation capability of the firm has direct effect on the innovation drivers ( e.g. technology advancement, globalization, and product life cycle). In this study, they also found the relationship between organizational innovation capabilities and corporate culture types (adhocracy, clan, market, and hierarchy). Previous researchers (Mujeeb \& Ahmad, 2011; Nevel, 2013; Zhu \& Engels, 2013), found that organizational culture is an essential driver of innovation.

Although essential and even noticeable in practice, innovation has not been explained as a business strategy in Pakistan, particularly in the banking sector. Here importantly, the question of organizational culture and its impact on organizational innovation capabilities also remains an unexplored area. This study will attempt to plug in the gap in the literature by looking at the role of organizational culture in promoting innovation in banks.

\section{Literature Review and Hypotheses Development}

Organizational culture builds a conducive working environment where all employees are satisfied and motivated, which is an essential attribute for innovation. According to Khan et al. (2019), organizational culture is influenced by national culture and personal characteristics. National culture and organizational culture have the same purpose as some specific behaviors are being encouraged at the workplace. In the workplace when people are working together, they create common beliefs, assumptions, and values which build an organizational culture (Jakopec \& Susanj, 2012). These beliefs, assumptions, and values must highlight the entire organizational operations and policies and these specific and unique behaviors, which are essential for the creation of organizational environment, should be encouraged at each level. Organizational culture builds the working environment which in-turn affects the employee motivation, innovation capabilities which are important for survival.

Expected behaviors and shared values of the employees can be presented in organizational culture, which creates creativity and innovation activities in the organization. Creativity and innovation are based on individual intent for creativity because it creates innovative ideas. It is assumed in the organizational culture that idea generation and implementation should be aligned for gaining success in the competitive markets (Balaceanu, 2010). Therefore, employee's behaviors influence organizational innovation capabilities and both these factors are influenced by the organizational culture collectively.

According to McLean (2005), mostly researchers suggested that innovation is only dependent on the individual capabilities and organizational culture did not play any vital role in the innovation process. On the other hand Donate and Guadamillas (2010) opined that organizational culture is an essential antecedent of innovation in the organization and organizational culture affect both individual and organizational innovation capabilities. Bouncken et al. (2009) discussed that idea generation and its implementation are not different and individual efforts of innovation will enhance more if their organizational culture is supportive for innovation.

Donate and Guadamillas (2010) further underpins that "shared assumptions, beliefs, and values are the individual factors of the organization whereas "structure, policies, procedures and practices" are organizational-level factors. These values help in designing organizational goals in the light of organizational culture, furthermore, the specific and acceptable behaviors are bound by the organizational culture values (Elsbach \& Stigliani, 2018), which foster innovation by introducing required behaviors, actions, policies and procedures which define the innovation in the organization (Atuahene \& Baiden, 2018). 
Few other researchers (e.g. Carvalho et al., 2018; Nuryasman \& Suryaman, 2018) suggested that organizational culture have a substantial effect on innovation. Skerlavaj et al., (2010) found in their study that there is a positive relationship between organizational culture and innovation. In another study on organizational culture and innovation, the researchers found that adhocracy culture has positive impact with radical innovation, whereas hierarchy culture is more suitable for new and improved innovations (NaranjoValencia et al., 2015).

Ahmed (1998) discussed the importance of organizational culture for nurturing innovation. The research pointed out that in the future, the companies which are highly focus on their employees and build an environment within the organization and foster innovation at every stage will be more progressive organizations. Claver et al. (1998) also discussed in their study that technological innovation requires different resources like material, financial, human and culture. The research focused that without organization culture the technical side of innovation will not be effective and technological innovation is considered as hardware whereas organizational culture is the software which runs the hardware more effectively.

Horibe (2001) expressed that the change process should start at the individual level as if s/he does not want to change, then the change process will be in vain. The innovation manager must build capacity, processes, and structures which support the innovation process. Tidd \& Bessant (2018) reviewed different research studies on innovation management and concluded that difficulties and unpredictability of environmental factors affect the overall innovation management process and organizational culture.

Johne (1999) discussed three types of innovation including product, process and market innovation. All those companies which want to survive in the future they must innovate according to the customer needs and wants, and the innovation process must be continuous. Similarly, Kaya et al., (2020) concluded that if a company want sustainability in the innovation of products they must improve dynamic capabilities which help in knowledge creation, imbibe the knowledge and sharing of knowledge. Knein et al, (2020) investigated 47 medium-sized companies in Germany and found that culture for innovation and psychological safety was positively correlated with return on asset and firm's goal achievement whereas culture and safety mediate the relationship between process innovation and organizational effectiveness.

Martin \& Terblanchi (2003) concluded that determinants of organizational culture like "strategy, organizational structure, support mechanism, individual behaviors which encourage innovation and internal communication are positively correlated with innovation and creativity in the organization." Jaskyte and Dressler (2005) investigated twenty non-profit organizations in the state of Alabama and found that organizational innovativeness is negatively correlated with "culture consensus" and positively related to "organizational culture dimensions of innovation and aggressiveness". The researchers included two control variables like size of the firm and leadership and concluded that cultural consensus is the key factor of prediction of organizational innovativeness.

\section{Hypotheses}

From the above literature review the following hypotheses are developed;

$\mathrm{H}_{1}$ : There is positive relationship between involvement culture and innovation.

$\mathrm{H}_{2}$ : There is negative relationship between consistency culture and innovation.

$\mathrm{H}_{3}$ : There is positive relationship between adaptability culture and innovation.

$\mathrm{H}_{4}$ : There is positive relationship between mission culture and innovation. 


\section{Theoretical Framework}

Quinn \& Rohrbaugh, (1983) presented a vital framework for investigating the organizational effectiveness in the United States. The researchers conducted their study in two stages. In the first stage, the organizational theorists and researchers are gathered and asked to provide criteria for organizational successes according to their experience and knowledge. In stage two, similar data have been collected from another group about organizational effectiveness. The researchers found that there were some factors same as stage 1 . These factors presented included value dimensions like internal-external, flexibility-control, and means-ends. These dimensions considered as a cornerstone for researcher to further validate. Cameron (1985) further extended the study of (Cameron, 1981) and (Quinn \& Rohrbaugh, 1983) by investigating 3406 respondents (i.e., head of departments and trustees) from 334 colleges and universities to find out the relationship between organizational culture types (like Clan, Market, Adhocracy, and hierarchy) and organizational effectiveness (presented by Quinn and his team) by collecting data through questionnaires. It was found that organizational culture types have a strong correlation with organizational effectiveness and other factors.

Quinn et al., (1991) studied the communication skills of the experts in the managerial context. The researchers analyzed 100 communication professors and evaluated business communication presentations in six different types. By using the "Competing value model," there are four different types of communication elaborated (namely "relational, informational, instructional, and transformational"). Denison \& Spreitzer (1991) provided an essential framework by a comparative analysis of different frameworks developed by (Cameron et al., 1991; Kimberly \& Quinn, 1984; Quinn \& Rohrbaugh, 1983; Zammuto \& Krakower, 1991). This study has two main perspectives i) psychometric analysis of two instruments based on competing for value framework and adopted Likert scale for measurement, and ii) investigating the effect of culture on the quality of individual's life. So the researchers found that across the four types of culture, scores are the best predictors of life quality particularly hierarchy culture has low profile than the other three types of culture.

Denison \& Mishra (1995) developed a model for measuring the relationship between organizational culture and organizational effectiveness. The model was based on four organizational culture traits (namely "involvement, consistency, adaptability, and mission"). The authors investigated these four traits by conducting two studies; i) identified the organizational traits and its relationship with effectiveness by conducting qualitative case studies analysis of five firms, ii) in other study data have been collected from CEOs of 764 companies in the USA for quantifying the relationship between organizational culture and effectiveness. Denison et al. (2006) Further refined the model developed by (Denison \& Mishra, 1995). The researchers used the same four organizational traits, i.e., "involvement, consistency, adaptability, and mission" and these traits further divided into three indices of each trait, and each index was comprised of 5 items. The instrument was validated through confirmatory factor analysis by collecting data from 35474 employees across 160 firms. Organizational effectiveness was measured by using five dimensions like "sale/ revenue growth, market share, profitability / ROA, quality of goods and services, new product development, and employee performance" and all these dimensions are rated through Likert scale starting from "low performer" to "high performer."

\section{Methodology}

\section{Sample and Data Collection}

The sample size was calculated through online sample size calculator for unknown population because we did not know the exact number of employees in the 25 banks throughout the country. The calculated sample size with $20 \%$ non-response was added because in this study online and manual data collection procedures were employed for data collection. A total of 309 questionnaires were received out of 400 distributed (response rate of 70\%). SPSS V24 and WarpPLS 7.0 were used for data analysis. 


\section{Measurement Scales}

After comprehensive literature review, the following reliable instruments were used in this study:

\section{Organizational Culture}

The instrument used to measure organizational culture was adopted from the Denison et al. (2006). This is a comprehensive instrument comprising of four different types of organizational culture (involvement, consistency, adaptability and mission) with twelve indices (empowerment, capability development, team orientation, core value, agreement, coordination and integration, creating change, customer focus, organizational learning, strategic direction and intent, goal orientation and vision). All the 12 indices have 60 items measured on a five-point Likert scale.

\section{Innovation}

The instrument for measuring innovation (dependent variable) was adapted from Wang and Ahmed (2004). There are 5 different constructs of innovation including product and service innovation, market innovation, process innovation, strategic innovation and behavioral innovation, and is comprised of 28 items having five-point Likert scale.

\section{Analysis}

\section{Demographics}

Table 1 shows the demographics of the collected data where majority of the respondents are male. The second variable age has the highest frequency of the age group between 30-39which means that the respondents are mature and have good knowledge about the organization.

Table 1 Demographics

\begin{tabular}{|llc|}
\hline & Sample Size $\mathbf{n = 3 0 9}$ & \\
\hline Variable & Category & Frequency \\
\hline \multirow{2}{*}{ Gender } & Male & 248 \\
& Female & 61 \\
& $20-29$ & 62 \\
Age & $30-39$ & 140 \\
& $40-49$ & 71 \\
& $>50$ & 20 \\
Marital Status & Not Mentioned & 16 \\
& Married & 224 \\
& Unmarried & 85 \\
Designation & Branch Manager & 92 \\
& Operation Manager & 73 \\
& Other & 58 \\
& Unit Head & 86 \\
Education & Bachelor & 27 \\
& Master & 235 \\
& MS/MPhil & 40 \\
& PhD & 6 \\
& Not Mentioned & 1 \\
\hline
\end{tabular}

The third variable designation shows that majority of the respondents are branch managers and unit heads which are the most suitable respondents in the banking sector and they are more knowledgeable than 
others. Majority of the respondents were highly qualified (Masters \& above) which means that there was no issue related to understanding the questionnaire.

\section{Reliability Analysis}

Table 2 shows a reliability analysis of the constructs. The threshold for composite reliability, Cronbach's alpha, Dijkastra's PLSc reliability, true composite reliability and factor reliability must be greater than 0.70 (Ibrahim et al., 2018). The reliability analysis shows that all the constructs have values in the acceptable range hence it shows that the instrument is reliable and can be used further for data collection purposes in Pakistani context.

Table 2 Reliability analysis of the latent variables

\begin{tabular}{|lccccc|}
\hline & Invol & Const & Adapt & Misn & Inno \\
\hline Composite reliability & 0.863 & 0.847 & 0.742 & 0.806 & 0.886 \\
Cronbach's alpha & 0.828 & 0.801 & 0.643 & 0.744 & 0.867 \\
Dijkstra's PLSc reliability & 0.833 & 0.807 & 0.659 & 0.817 & 0.917 \\
True composite reliability & 0.863 & 0.847 & 0.742 & 0.806 & 0.886 \\
Factor reliability & 0.863 & 0.847 & 0.742 & 0.806 & 0.886 \\
\hline
\end{tabular}

Invol=Involvement, Const= Consistency, Adapt=adaptability, Misn=Mission, Inno=Innovation

\section{Correlation Analysis}

Table 3 depicts correlation between constructs and average variance extracted (AVE). The acceptable criteria for AVE > 0.50 hence all the diagonal values enclosed in the brackets reveal that the AVE value for all the relationships between constructs are in acceptable range. The correlation analysis shows all the constructs have positive correlation with each other.

Table 3 Correlations among latent variables with AVE

\begin{tabular}{|lccccccc|}
\hline & Mean & SD & Invol & Const & Adapt & Misn & Inno \\
\hline Invol & 3.29 & 0.93 & $(0.66)$ & 0.26 & 0.38 & 0.66 & 0.63 \\
Const & 1.92 & 1.87 & 0.26 & $(0.58)$ & 0.41 & 0.31 & 0.29 \\
Adapt & 3.21 & 0.87 & 0.38 & 0.41 & $(0.62)$ & 0.34 & 0.42 \\
Misn & 3.27 & 0.91 & 0.66 & 0.31 & 0.34 & $(0.52)$ & 0.61 \\
Inno & 3.23 & 0.88 & 0.63 & 0.29 & 0.42 & 0.61 & $(0.59)$ \\
\hline
\end{tabular}

Note: p-value of all correlations are $<0.001$ and square roots of average variances extracted (AVEs) shown on diagonal.

\section{Factor Loading and Cross Loading}

The construct's items show a good factor loading of items are greater than 0.70 which are within acceptable range. The results of the normalized and cross loading are annexed in appendix 1.

\section{Model Fitness and Quality Indices}

WarpPLS7.0 being used in this study showed the following model fitness measures; 
Table 4 Model Fitness and quality indices

\begin{tabular}{|lccc|}
\hline Indices & Value & P-Value & Threshold \\
\hline Average Path Coefficient(APC) & 0.216 & $<0.001$ & \\
Average R-Squared(ARS) & 0.488 & $<0.001$ & \\
Average Adjusted R-Squared(AARS) & 0.481 & $<0.001$ & \\
Average block VIF (AVIF) & 1.576 & & \\
Average Full Collinearity (AFVIF) & 1.749 & acceptable if $<=5$, ideally $<=3.4$ \\
Tenenhaus GoF (GoF) & 0.37 & small $>=0.1$, medium $>=0.25$, large $>=0.36$ \\
Sympson's paradox ratio (SPR) & 1 & acceptable if $>=0.7$, ideally $=1$ \\
R-squared contribution ratio (RSCR) & 1 & acceptable if $>=0.9$, ideally $=1$ \\
Statistical suppression ratio (SSR) & 1 & & acceptable if $>=0.7$ \\
\hline
\end{tabular}

The above table shows that APC has the value of 0.216 with the p-value $<0.001$, ARS has the value 0.488 with $\mathrm{p}$ value of $<0.001$ and AARS has the value 0.481 with $\mathrm{p}$ value $<0.001$. The AVIF and AFVIF value is 1.749 which are below 3.4 means there is no collinearity problem in the data. GoF developed by Tenenhaus et al. (2000) which is also called global goodness of fit index has the value 0.37 which means that the model has large explanatory power. SPR is the most important index that tests whether there are paradoxes in the model or not, the value of SPR for our data is 1 which shows that the model is free from the paradoxes. RSCR has the value 1 which shows that the model is exempted from the negative $\mathrm{R}^{2}$ contribution, the value of SSR is 1 which shows that all the data are exempted from statistical suppression.

\section{Hypothesis Testing}

Table 4 shows the hypothesis testing/results in summarized form. The first hypothesis has the value 0.359 with probability value of $<0.001$ which shows that there is statistically significant positive relationship between involvement culture and innovation. This means that when organization empower their employees, work on continuously on capability development programs and building teams for operations then innovation activities will be higher than others who does not have emphasis on these activities. High involvement of the employees is thus required for high innovation in banks.

The second hypothesis is also accepted and shows that the consistency in the internal organization's operations negatively affect the innovation in the organization, it has the value -0.237 with $p$ value $<0.001$ which is highly significant relationship between consistency culture and innovation. The third hypothesis adaptability has positive relationship with innovation is accepted with beta value of 0.168 ( $p$-value $<0.001$ ) is statistically significant relationship between adaptability culture and innovation. When there is adaptability in organization and they incorporate the changes in their operations easily, they behave as innovative firms.

Table 4 Hypothesis testing / results

\begin{tabular}{|lcccl|}
\hline Predictors & Dependent & $\boldsymbol{\beta}$ & P-Value & Decision \\
\hline Invol & & 0.359 & $<0.001$ & Supported \\
Const & & -0.237 & $<0.001$ & Supported \\
Adapt & Inno & 0.168 & $<0.001$ & Supported \\
Misn & & 0.299 & $<0.001$ & Supported \\
\hline
\end{tabular}

Invol (Involvement), Const (Consistency), Adapt(Adaptability), Misn (Mission), Inno (Innovation) 
They can manage the environmental and technological changes and thus can earn more profits by incorporating changes on time. The forth hypothesis mission culture has positive relationship with innovation in banks is accepted with the beta value 0.299 (p-value $<0.001$ ) which is highly significant and shows that mission culture in the banks positively affect innovation activities.

\section{Discussion}

Organizational culture is the most important internal factor for innovation in the organization. Our results deduce that the banks which focus more on involvement, adaptability and mission culture will be more innovative (with more pace) and which in-turn will increase the value of the firm. These banks will be thus proactive to incorporate the changes in the internal environment and changes can be easily adapted so they can grab good opportunities in the market. The other way round, if there is a status quo or consistency in the operations and they are reluctant to change their policies, structures, behaviors etc., then there will be less innovation and they will face low growth, low financial performance and low market share because as they may not have the competitive edge to take care of the customized customer needs which other banks may be doing. Few researcher like (Lijauco et al., 2020; Sánchez-Báez et al., 2020; Sharifirad et al., 2012; Zanella et al., 2019) studies these relationships with innovation in different companies which is further validated by the current study.

\section{Limitations and Future Research Directions}

This study also has few limitations for example individual organizational culture has not been assessed, longitudinal research not conducted and comparative analysis has not been done between different types of banks like public and private banks, conventional and Islamic banks. Only scheduled banks are included in the sample size. The future researchers may assess the individual organizational culture of each bank for a comprehensive study, take the challenge of longitudinal study, can use a mix method approach and may study the impact of COVID-19 on the organizational culture of the banks. A comparative study with other related organizations for example insurance should also be considered.

\section{References}

Ahmed, P. K. (1998). Culture and climate for innovation. European Journal of Innovation Management, l(1), 30-43.

Allaire, Y., \& Firsirotu, M. E. (1984). Theories of organizational culture. Organization Studies, 5(3), 193226.

Atuahene, B. T., \& Baiden, B. K. (2018). Organizational culture of Ghanaian construction firms. International Journal of Construction Management, 18(2), 177-188.

Balaceanu, V. A. (2010). Marketing technological innovations in banking products and services. Challenges of the Knowledge Society. Economy, 1224-1230.

Bouncken, R. B., Zagvozdina, J., Golze, A., \& Mrozewska, A. (2009). A comparative study of cultural influences on intentions to found a new venture in Germany and Poland. International Journal of Business and Globalisation, 3(1), 47-63.

Cameron, K. S. (1981). Domains of organizational effectiveness in colleges and universities. Academy of Management Journal, 24(1), 25-47.

Cameron, K. S. (1985). Cultural Congruence, Strength, and Type: Relationships to Effectiveness. ASHE 1985 Annual Meeting Paper. In Annual Meeting of the CO Associations for the Study of Higher Education : Vol. HE 018508 (Issue 01, pp. 1-52). Natiohal Inst. of Education (.ED).

Cameron, K. S., Freeman, S. J., \& Mishra, A. K. (1991). Best practices in white-collar downsizing: Managing contradictions. Academy of Management Perspectives, 5(3), 57-73.

Carvalho, C. R. S. P., Castro, M. A. R., Silva, L. P., \& Carvalho, L. O. P. (2018). The relationship between organizational culture, organizational commitment and job satisfaction. REBRAE, 11(2), 201-215. 
Claver, E., Llopis, J., Garcia, D., \& Molina, H. (1998). Organizational culture for innovation and new technological behavior. The Journal of High Technology Management Research, 9(1), 55-68.

Denison, D. R., \& Mishra, A. K. (1995). Toward a theory of organizational culture and effectiveness. Organization Science, 6(2), 204-223.

Denison, D. R., \& Spreitzer, G. M. (1991). Organizational culture and organizational development: A competing values approach. Research in Organizational Change and Development, 5(1), 1-21.

Denison, Janovics, Young, \& Cho. (2006). Diagnosing organizational cultures: Validating a model and method. Documento de Trabajo. Denison Consulting Group, 1-39.

Donate, M. J., \& Guadamillas, F. (2010). The effect of organizational culture on knowledge management practices and innovation. Knowledge and Process Management, 17(2), 82-94. https://doi.org/10.1002/kpm.344

Elsbach, K. D., \& Stigliani, I. (2018). Design Thinking and Organizational Culture: A Review and Framework for Future Research. Journal of Management, 0149206317744252.

Horibe, F. (2001). Creating the innovation culture. John Wiley \& Sons.

Ibrahim, N., Fairuz Shiratuddin, M., \& Wai Wong, K. (2018). Instruments for Measuring the Influence of Visual Persuasion: Validity and Reliability Tests. Online) European Journal of Social Sciences Education and Research, 2(3), 25-37.

Jakopec, A., \& Susanj, Z. (2012). Organizational innovation diagnosis: A case study. Economy of Eastern Croatia Yesterday, Today, Tommorow, 1(5), 71-78.

Jaskyte, K., \& Dressler, W. W. (2005). Organizational culture and innovation in nonprofit human service organizations. Administration in Social Work, 29(2), 23-41.

Johne, A. (1999). Successful market innovation. European Journal of Innovation Management, 2(1), 6-11.

Kaya, B., Abubakar, A. M., Behravesh, E., Yildiz, H., \& Mert, I. S. (2020). Antecedents of innovative performance: Findings from PLS-SEM and fuzzy sets (fsQCA). Journal of Business Research, 114, 278-289.

Khan, M. K., Kaleem, A., Zulfiqar, S., \& Akram, U. (2019). Innovation investment: Behaviour of Chinese firms towards financing sources. International Journal of Innovation Management, 23(7), 1-29.

Kimberly, J. R., \& Quinn, R. E. (1984). Managing organizational transitions. McGraw-Hill/Irwin.

Knein, E., Greven, A., Bendig, D., \& Brettel, M. (2020). Culture and cross-functional coopetition: The interplay of organizational and national culture. Journal of International Management, 26(2), 100120.

Lijauco, F., Gajendran, T., Brewer, G., \& Rasoolimanesh, S. M. (2020). Impacts of Culture on Innovation Propensity in Small to Medium Enterprises in Construction. Journal of Construction Engineering and Management, 146(3), 1-15. https://doi.org/10.1061/(ASCE)CO.1943-7862.0001753

Martins, E. C., \& Terblanche, F. (2003). Building organisational culture that stimulates creativity and innovation. European Journal of Innovation Management, 6(1), 64-74.

McLean, L. D. (2005). Organizational culture's influence on creativity and innovation: A review of the literature and implications for human resource development. Advances in Developing Human Resources, 7(2), 226-246.

Mujeeb, E. ul, \& Ahmad, M. S. (2011). Impact of Organizational Culture on Performance Management Practices in Pakistan. International Management Review, 7(2), 52-57.

Naranjo-Valencia, J. C., Jimenez, D. J., \& Sanz-Valle, R. (2015). Studying the links between organizational culture, innovation, and performance in Spanish companies. Revista Latinoamericana de Psicología, 48, 30-41.

Nevel, K. M. (2013). Exploring The Relationship Between Organizational Culture And Value Innovation In A Supply Chain Logistics Company. In School of Graduate Studies: Vol. Doctor of (Issue 3591097). Alvernia University.

Nuryasman, M. N., \& Suryaman, E. A. (2018). The influence of organizational culture and work motivation toward employee performance (case study on employees of PT Inoac Polytechno Indonesia). Journal Manajemen, 22(1), 74-90.

Quinn, R. E., Hildebrandt, H. W., Rogers, P. S., \& Thompson, M. P. (1991). A competing values framework for analyzing presentational communication in management contexts. The Journal of 
Business Communication, 28(3), 213-232.

Quinn, R. E., \& Rohrbaugh, J. (1983). A spatial model of effectiveness criteria: Towards a competing values approach to organizational analysis. Management Science, 29(3), 363-377.

Rahman, H. (2014). The Mediating Effects of Employees' Career Issues on the Relationships between Organizational Learning Culture and Employees' Perceived Job Performance. In Business Administration: Vol. Doctrate (Issue 7414). Preston University .

Sánchez-Báez, E. A., Fernández-Serrano, J., \& Romero, I. (2020). Organizational culture and innovation in small businesses in Paraguay. Regional Science Policy and Practice, 12(2), 233-247. https://doi.org/10.1111/rsp3.12203

Schein, E. H. (1990). Organizational culture (Vol. 45, Issue 2). American Psychological Association.

Sharifirad, M. S., Ataei, V., Sadegh Sharifirad, M., \& Ataei, V. (2012). Organizational culture and innovation culture: exploring the relationships between constructs. Leadership \& Organization Development Journal, 33(5), 494-517.

Skerlavaj, M., Song, J. H., \& Lee, Y. (2010). Organizational Learning Culture, Innovative Culture and Innovations in South Korean Firms. Expert Systems with Applications, 37, 6390-6403.

Tenenhaus, M., Amato, S., \& Vinzi, V. E. (2000). A global Goodness - of - Fit index for PLS structural. Proceedings of the XLII SIS Scientific Meeting, 1(2), 739-742.

Tidd, J., \& Bessant, J. R. (2018). Managing innovation: integrating technological, market and organizational change. John Wiley \& Sons.

Wang, C. L., \& Ahmed, P. K. (2004). The development and validation of the organisational innovativeness construct using confirmatory factor analysis. European Journal of Innovation Management, 7(4), 303-313.

Zammuto, R. F., \& Krakower, J. Y. (1991). Quantitative and qualitative studies of organizational culture.

Zanella, C. C., Vieira, R., \& Lemos, C. (2019). Interfaces between organizational culture and innovation in micro and small companies. REGMPE, 4(3), 53-72.

Zheng, C. (2009). A correlational study of organizational innovation capability and two factors: Innovation drivers and organizational culture: Vol. Ph.D (Issue 3394575). University of Phoenix.

Zhu, C., \& Engels, N. (2013). Organizational culture and instructional innovations in higher education: Perceptions and reactions of teachers and students. Educational Management Administration \& Leadership, 42(1), 136-158. 
Appendix 1

\begin{tabular}{|c|c|c|c|c|c|}
\hline \multicolumn{6}{|c|}{ Factor Loadings and cross-loadings } \\
\hline & Invol & Cont & Adapt & Misn & Inno \\
\hline EMP1 & 0.83 & -0.16 & 0.02 & -0.04 & -0.34 \\
\hline EMP2 & 0.66 & -0.07 & -0.19 & 0.04 & 0.57 \\
\hline EMP3 & 0.70 & 0.03 & -0.25 & 0.04 & 0.12 \\
\hline EMP4 & 0.72 & -0.01 & -0.04 & 0.02 & -0.11 \\
\hline EMP5 & 0.69 & -0.03 & 0.00 & -0.17 & 0.27 \\
\hline TO1 & 0.65 & 0.08 & 0.08 & 0.16 & 0.12 \\
\hline TO2 & 0.78 & -0.13 & 0.15 & -0.12 & -0.29 \\
\hline TO3 & 0.69 & -0.08 & 0.26 & -0.47 & 0.09 \\
\hline TO4 & 0.78 & 0.03 & 0.03 & -0.04 & -0.33 \\
\hline TO5 & 0.76 & -0.09 & 0.04 & 0.09 & -0.31 \\
\hline CD1 & 0.61 & 0.31 & -0.03 & -0.45 & 0.60 \\
\hline CD2 & 0.72 & 0.02 & 0.12 & -0.31 & -0.03 \\
\hline CD3 & 0.50 & 0.20 & -0.17 & 0.85 & 0.44 \\
\hline CD4 & 0.61 & 0.20 & -0.28 & 0.79 & 0.01 \\
\hline CVLS1 & -0.17 & 0.81 & 0.17 & 0.23 & -0.08 \\
\hline CVLS2 & -0.06 & 0.89 & -0.03 & -0.20 & 0.15 \\
\hline CVLS3 & -0.14 & 0.82 & 0.34 & 0.06 & -0.14 \\
\hline CVLS5 & -0.11 & 0.80 & -0.07 & 0.20 & 0.04 \\
\hline AGT1 & -0.13 & 0.81 & -0.08 & -0.16 & 0.39 \\
\hline AGT2 & -0.01 & 0.89 & -0.06 & 0.05 & -0.11 \\
\hline AGT3 & -0.29 & 0.86 & -0.11 & 0.06 & 0.25 \\
\hline AGT5 & -0.02 & 0.87 & 0.04 & 0.06 & -0.14 \\
\hline CNI1 & 0.27 & 0.79 & -0.02 & -0.24 & 0.07 \\
\hline CNI2 & 0.44 & 0.85 & 0.02 & -0.33 & -0.19 \\
\hline CNI3 & 0.21 & 0.83 & -0.14 & -0.35 & -0.11 \\
\hline CNI4 & -0.12 & 0.71 & 0.04 & -0.60 & -0.05 \\
\hline CNI5 & 0.22 & 0.75 & -0.27 & 0.32 & -0.18 \\
\hline CCNG1 & 0.05 & -0.25 & 0.78 & -0.58 & 0.35 \\
\hline CCNG2 & 0.05 & -0.05 & 0.92 & -0.35 & 0.43 \\
\hline CCNG3 & 0.40 & -0.10 & 0.81 & -0.42 & 0.39 \\
\hline CCNG4 & 0.21 & 0.01 & 0.78 & -0.82 & 0.31 \\
\hline CCNG5 & 0.29 & 0.06 & 0.92 & 0.34 & 0.27 \\
\hline CSFS1 & -0.11 & -0.13 & 0.92 & 0.03 & -0.22 \\
\hline CSFS2 & 0.09 & -0.09 & 0.96 & -0.39 & -0.15 \\
\hline CSFS3 & 0.17 & 0.17 & 0.81 & -0.21 & -0.09 \\
\hline CSFS4 & -0.01 & -0.39 & 0.82 & -0.14 & -0.35 \\
\hline CSFS5 & 0.26 & 0.08 & 0.88 & 0.04 & -0.60 \\
\hline OGLR1 & -0.12 & -0.09 & 0.82 & 0.39 & -0.31 \\
\hline OGLR2 & -0.04 & 0.62 & 0.70 & -0.15 & 0.12 \\
\hline OGLR3 & -0.41 & -0.30 & 0.99 & 0.25 & -0.11 \\
\hline OGLR4 & -0.31 & 0.26 & 0.68 & 0.65 & -0.05 \\
\hline OGLR5 & -0.04 & 0.04 & 0.74 & 0.32 & -0.11 \\
\hline SDNI1 & 0.06 & 0.08 & -0.06 & 0.73 & -0.17 \\
\hline
\end{tabular}




\begin{tabular}{|c|c|c|c|c|c|}
\hline SDNI2 & -0.29 & -0.10 & 0.77 & 0.49 & -0.25 \\
\hline SDNI3 & 0.95 & 0.03 & -0.11 & 0.63 & -0.27 \\
\hline SDNI4 & 0.70 & 0.29 & -0.07 & 0.66 & -0.28 \\
\hline SDNI5 & 0.16 & -0.68 & -0.43 & 0.48 & 0.30 \\
\hline GONT1 & -0.42 & 0.06 & 0.18 & 0.71 & 0.13 \\
\hline GONT2 & 0.57 & -0.26 & 0.41 & 0.62 & 0.24 \\
\hline GONT3 & -0.14 & -0.06 & 0.04 & 0.73 & 0.05 \\
\hline GONT4 & -0.17 & -0.06 & -0.06 & 0.71 & 0.04 \\
\hline GONT5 & -0.43 & -0.01 & -0.02 & 0.76 & 0.14 \\
\hline VSN1 & -0.06 & 0.00 & -0.19 & 0.75 & -0.07 \\
\hline VSN2 & 0.43 & -0.10 & -0.21 & 0.66 & 0.24 \\
\hline VSN3 & 0.12 & -0.13 & 0.70 & 0.61 & -0.11 \\
\hline VSN4 & -0.04 & 0.02 & -0.01 & 0.74 & -0.13 \\
\hline VSN5 & -0.31 & -0.10 & -0.14 & 0.68 & 0.43 \\
\hline PSI1 & -0.28 & 0.05 & -0.05 & 0.17 & 0.71 \\
\hline PSI2 & -0.34 & 0.06 & -0.09 & 0.24 & 0.72 \\
\hline PSI3 & -0.11 & -0.07 & 0.03 & -0.09 & 0.74 \\
\hline PSI4 & -0.03 & -0.83 & 0.14 & 0.53 & 0.16 \\
\hline PSI5 & 0.27 & -0.12 & 0.14 & -0.59 & 0.79 \\
\hline MI1 & -0.09 & 0.07 & -0.11 & -0.15 & 0.76 \\
\hline MI2 & 0.71 & -0.23 & 0.21 & -0.44 & 0.71 \\
\hline MI3 & 0.48 & 0.07 & 0.16 & -0.14 & 0.63 \\
\hline MI4 & 0.27 & -0.17 & -0.02 & -0.16 & 0.71 \\
\hline MI5 & -0.26 & -0.16 & 0.20 & -0.31 & 0.83 \\
\hline PRI1 & 0.28 & 0.09 & -0.38 & 0.69 & 0.60 \\
\hline PRI2 & 0.29 & 0.10 & 0.08 & -0.29 & 0.68 \\
\hline PRI3 & -0.06 & -0.03 & -0.06 & 0.05 & 0.72 \\
\hline PRI4 & -0.07 & 0.30 & 0.09 & 0.06 & 0.64 \\
\hline PRI5 & 0.64 & -0.08 & -0.15 & -0.13 & 0.63 \\
\hline PRI6 & 0.60 & 0.09 & 0.31 & -0.68 & 0.56 \\
\hline PRI7 & 0.48 & 0.07 & 0.28 & -0.51 & 0.65 \\
\hline PRI8 & 0.20 & -0.18 & 0.19 & -0.15 & 0.68 \\
\hline SI1 & -0.05 & 0.00 & 0.01 & -0.62 & 0.78 \\
\hline SI2 & -0.08 & -0.13 & 0.03 & 0.19 & 0.71 \\
\hline SI3 & 0.03 & -0.12 & 0.02 & -0.09 & 0.74 \\
\hline SI4 & 0.18 & 0.06 & 0.63 & -0.23 & 0.78 \\
\hline SI5 & -0.31 & -0.33 & 0.10 & 0.52 & 0.69 \\
\hline BI1 & -0.44 & 0.04 & -0.03 & 0.53 & 0.67 \\
\hline BI2 & -0.01 & 0.04 & 0.43 & -0.70 & 0.63 \\
\hline BI3 & -0.06 & -0.06 & 0.47 & -0.61 & 0.68 \\
\hline BI4 & 0.37 & 0.19 & -0.17 & -0.14 & 0.66 \\
\hline BI5 & 0.04 & 0.17 & -0.34 & 0.61 & 0.62 \\
\hline
\end{tabular}

